\section{Novel treatment of a gastric Dieulafoy lesion with an over-the-scope clip}

A 74-year-old man presented with recurrent obscure, overt, life-threatening gastrointestinal bleeding. Esophagogastroduodenoscopy (EGD) showed blood in the fundus and a nonbleeding Dieulafoy lesion at the lesser curvature of the stomach ( Fig. 1). Due to the tangential position and large size of the lesion, thermal therapy or through-the-scope clipping were not carried out and an over-thescope clip (Ovesco, Tübingen, Germany) was successfully deployed across the le$\operatorname{sion}(\bullet$ Fig. 2).

A Dieulafoy lesion is a congenital defect consisting of an abnormally large, tortuous submucosal artery that has the potential to bleed through a small mucosal defect and is typically found in the lesser curvature of the stomach. At times, traditional methods for treating the lesion can be unsuccessful. An over-the-scope clip (Ovesco, Tübingen, Germany) has been developed for the closure of small mural defects [1]. It is thought to obtain a more sturdy closure compared with endoclips due to its capacity to grasp more visceral tissue and apply a greater compressive force.

The is the first case report from North America describing the use of the overthe-scope clipping device for the management of a Dieulafoy lesion. Animal and cadaveric trials have shown the over-thescope clip to be more effective for spurting arterial bleeding [2]. Mangiavillano and colleagues published the first video report of over-the-scope clip treatment of a refractory Dieulafoy lesion [3]. Kratt and colleagues described a success rate of $94.2 \%$ with the over-the-scope clip in 60 patients with various causes of gastrointestinal bleeding, including three Dieulafoy lesions [4]. Kirschniak and colleagues reviewed 50 patients treated at a single center for dif-

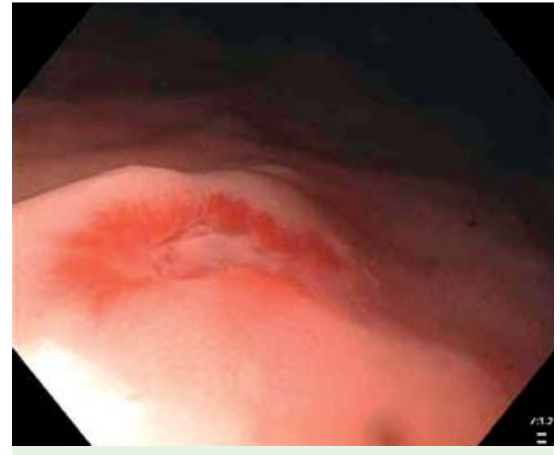

Fig. 1 Dieulafoy lesion in the lesser curvature of stomach of a 74-year-old man with recurrent obscure, overt, life-threatening gastrointestinal bleeding.

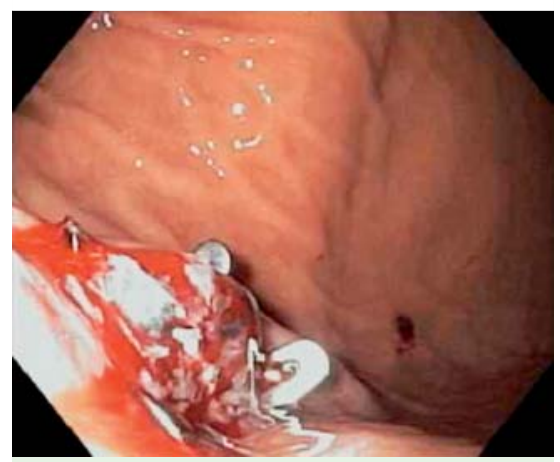

Fig. 2 Deployment of the over-the-scope clip.

ferent indications with the over-the-scope clip, including hemostasis and perforations [5]. The primary treatment was successful in all cases, including one gastric Dieulafoy. The over-the-scope clip may have the potential for being part of the routine armamentarium for endoscopic control of large vascular ectasias.

Endoscopy_UCTN_Code_TTT_1AO_2AD

Competing interests: None

\section{Gómez, K. R. Kyanam Kabir Baig, F. J. Lukens, T. Woodward}

Department of Gastroenterology and Hepatology, Mayo Clinic, Jacksonville, Florida, USA

\section{References}

1 Kirschniak A, Kratt T, Stuker D et al. A new endoscopic over-the-scope clip system for treatment of lesions and bleeding in the GI tract: first clinical experience. Gastrointest Endosc 2007; 66: $162-167$

2 Naegel A, Bolz J, Zopf Y et al. Hemodynamic efficacy of the over-the-scope clip in an established porcine cadaveric model for spurting bleeding. Gastrointest Endosc 2012; 75: $152-159$

3 Mangiavillano B, Arena M, Morandi E et al. Trattamento con OVESCO ${ }^{\circledR}$ di una Dieulafoy gastrica resistente a multipli trattamenti endoscopici tradizionali. 2012; Available at: www.siedwebtv.it, Accessed October 1, 2012

4 Kratt $T$, Stüker $D$, Küper $M$ et al. Das OverThe-Scope-Clip-System (OTSC): Erfahrungen in der klinischen Anwendung bei $60 \mathrm{~Pa}$ tienten. Z Gastroenterol 2010; 48: 584

5 Kirschniak A, Subotova N, Zieker D et al. The Over-The-Scope Clip (OTSC) for the treatment of gastrointestinal bleeding, perforations, and fistulas. Surg Endosc 2011; 25: $2901-2905$

Bibliography

DOI http://dx.doi.org/

10.1055/s-0032-1326073

Endoscopy 2013; 45: E71

(c) Georg Thieme Verlag KG

Stuttgart · New York

ISSN 0013-726X

Corresponding author

V. Gómez

Mayo Clinic

4500 San Pablo Road South

Jacksonville

FL 32224

USA

Fax: +1-904-9536225

gomez.victoria@mayo.edu 